\title{
Teaching of direct posterior resin composite restorations in UK dental therapy training programmes
}

IN BRIEF

- Appreciate the role of dental therapists in the delivery of operative dentistry treatments.

- Be aware of the level of training and knowledge of operative dentistry treatments amongst contemporary dental therapy graduates.

- Be familiar with current evidence and techniques for placing posterior composites.

\author{
C. D. Lynch ${ }^{1}$ and N. H. F. Wilson²
}

\begin{abstract}
Aim With the number of dental therapists involved in the delivery of dental care in the UK on the increase, and the trend towards the use of direct resin composites (composites) for the restoration of posterior teeth, this study was undertaken to describe the teaching of posterior composites in dental therapy training programmes in the UK. A secondary aim was to identify differences in techniques for posterior composites taught within these dental therapy training programmes. Methods In 2008/9, a questionnaire seeking information on the teaching of posterior composites was distributed by email to 13 centres with dental therapy training programmes in the UK. This questionnaire sought information relating to the teaching of direct posterior composites to dental therapy students, including the amounts of preclinical and clinical teaching in respect of deciduous and permanent teeth, numbers of restorations placed, contraindications to placement, and details in respect of operative techniques. Results Ten completed responses were received (response rate $=77 \%$ ). In ten programmes, student dental therapists received clinical training in the placement of composite restorations in the occlusal surfaces of premolar and permanent molar teeth, and nine programmes included such training for two and three surface occlusoproximal restorations. The mean proportions of posterior restorations placed clinically by student dental therapists in permanent teeth using dental amalgam and composite were 52\% and 46\% respectively (range: amalgam $=20-95 \%$; composite $=5-70 \%)$. Conclusion With the exception of one programme, the teaching of posterior composites is a well established element of dental therapy training. Some variations were noted in the teaching of clinical techniques between respondent training centres. It is suggested that to ensure harmony in approaches to treatments provided by graduated therapists that training centres look to relevant consensus documents, such as those of the British Association of Teachers of Conservative Dentistry. The findings of our study are important for the future provision of oral healthcare, given the growing evidence base in favour of minimally invasive dentistry.
\end{abstract}

\section{INTRODUCTION}

The concept of the dental team is now well established, with a team approach to oral healthcare provision being considered to be in the best interests of patients. ${ }^{1}$ Recently, there has been an expansion in the scope of practice and numbers of dental therapists involved in the delivery of dental care within the United Kingdom. ${ }^{2}$ Following guidance from the General Dental Council (GDC)

${ }^{1 *}$ Senior Clinical Lecturer/ Honorary Consultant in Restorative Dentistry, Tissue Engineering \& Reparative Dentistry, School of Dentistry, Cardiff University, Heath Park, Cardiff, CF14 4XY; ${ }^{2}$ Professor of Restorative Dentistry, King's College London Dental Institute, London *Correspondence to: Dr Christopher D Lynch Email: Iynchcd@cardiff.ac.uk

\section{Refereed Paper}

Accepted 26 March 2010

DOI: 10.1038/sj.bdj.2010.399

${ }^{\circ}$ British Dental Journal 2010; 208: 415-421 and given the structure of dental care professional (DCP) training programmes, most dental therapists trained within the UK are dually-qualified dental hygienisttherapists. ${ }^{3}$ As such, the range of clinical procedures that most registered dental therapists may perform under prescription from a registered dentist include periodontal care, preventive dentistry, extraction of deciduous teeth, impression-making, and placement of simple (no pulpal involvement) direct restorations of different materials including resin composites (composites). ${ }^{4,5}$ At the time of writing, 1,363 dental therapists were listed on the GDC's DCP register. ${ }^{6}$ While the awareness of the role of dental therapists is poor among the general public, ${ }^{1}$ their involvement in the delivery of primary dental care is increasing, against a backdrop of considerable potential.
Traditionally, dental amalgam was considered to be the 'material of choice' for direct placement in the restoration of posterior teeth. Twenty years ago composites were viewed with suspicion in relation to their suitability for the restoration of, in particular, load-bearing surfaces in posterior teeth. Consensus guidance from the mid-1990s recommended that the placement of composites in load-bearing posterior situations should be '...limited to the occlusal surfaces of premolars, and preferably those with limited occlusal function..." Following, among other factors, improvement in the properties and handling characteristics of composite materials, the development of increasingly predictable bonding technologies, increased understanding of the ways in which adhesives and resins should be applied, increased demands from patients for aesthetic 
minimally invasive restorations, there has been a significant increase in the number of posterior composites placed in general dental practice. ${ }^{8-10}$ Surveys illustrate that one half of UK dentists place composites in the occlusal surfaces of premolar and permanent molar teeth, ${ }^{11}$ with clinical evidence suggesting that the longevity of posterior composite restorations may now be found to match that of posterior amalgam restorations. ${ }^{12,13}$ Furthermore, surveys of dental school training programmes demonstrate that the teaching of posterior composite restorations have increased by almost two-fold during the past ten years. ${ }^{14}$ Clearly, the popularity and confidence in posterior composite restorations are set to increase in the future.

While the nature of teaching and extent of clinical experience with posterior composites has been documented for dental students, ${ }^{14}$ little information exists on the teaching of posterior composites to, among others, student dental therapists. The primary aim of this study was to describe the teaching of direct posterior composites to student dental therapists in UK training programmes. A secondary aim of the study was to identify differences between training centres, if any, in techniques for posterior composites taught to student dental therapists in the UK.

\section{MATERIALS AND METHODS}

In 2008/09, an email invitation was sent to the 17 dental therapy training centres in the UK inviting them to participate in the study. Fourteen centres agreed to participate, and were sent a questionnaire seeking information in relation to the teaching of direct posterior composites to dental therapy students. The information sought included:

- The nature of the dental therapy training programme in each school

- Overall curriculum time devoted to the teaching of posterior composites and the proportions of composite restorations placed in deciduous and permanent posterior teeth

- Staff responsible for directing and delivering this teaching

- Relevant clinical techniques taught, including cavity preparation, contraindications taught, moisture control, the use of bases and liners, matrix and wedge selection, commercial brands of composite and bonding agents used in teaching programmes, light curing techniques, finishing techniques and fees charged, if any, for student therapist treatments.

Both 'open' questions (where respondents were given some space in which to write a textual response to a question) and 'closed' questions (where respondents were given a number of possible responses to a statement and asked to identify the most appropriate one) were used.

Non-respondents were followed up by email. Information received was entered onto a Microsoft Excel datasheet for the purpose of obtaining and reporting descriptive statistics.

\section{RESULTS}

Completed responses were received from ten of the 14 centres included in the study (response rate $=72 \%$ ). While all 17 centres were initially contacted, only 14 agreed to do so. While it is not possible for reasons of confidentiality to divulge the names of the schools involved, based on current information the three non-participating schools accounted for ca. 15\% of the graduating dental therapist workforce each year in the UK. ${ }^{5}$ The four 'non-responder' schools (those who agreed to participate and then failed to return a questionnaire) accounted for ca. 23\% of the graduating dental therapist workforce each year. ${ }^{5}$ This means that the participating schools provided information in relation to $62 \%$ of the annual graduating dental therapist workforce in the UK. It is understood that the questionnaires were completed by the person with overall responsibility for the dental therapy training programme in each centre.

\section{The training programmes}

Of the ten respondent centres, three were situated in Scotland, one in Wales and six in England. The mean number of dental therapists graduating from each centre was 15.8 per annum (range $=5$-30). Four centres anticipated an increase in their number of dental therapy students over the next five years, three of which anticipated increased funding with an increase in student numbers. The remaining two centres anticipated the introduction of student self-financed training programmes for dental therapists over the next five years.
In all ten schools the existing dental therapy training programme was a combined dental hygiene-therapy programme. One school additionally ran a part-time dental therapy training programme for individuals who have previously trained and qualified as dental hygienists.

\section{Teaching - permanent teeth}

All ten centres taught the placement of preventive resin restorations and composite occlusal restorations in premolar and permanent molar teeth. Nine centres taught the placement of two and three surface occlusoproximal composite restorations in premolars and permanent molar teeth. One centre did not teach occlusoproximal composite restorations and did not intend to introduce the teaching of such restorations over the next five years.

The respondent centres reported that the teaching of posterior composites in permanent teeth accounted for 34\% of the preclinical course in operative dentistry (range = 20-60\%), while the time devoted to the teaching of posterior amalgam restorations accounted for 39\% of the preclinical course (range $=20-80 \%$ ). It was anticipated over the next five years that the teaching of posterior composites will increase by approximately one third to account for $45-50 \%$ of the preclinical course (range $=25-75 \%$ ), while the teaching of posterior amalgams will decrease by a similar amount to account for $25-30 \%$ of the preclinical programme (range $=10-40 \%$ ). Five of the ten centres reported that they taught amalgam placement before teaching posterior composite placement. Only one of the remaining centres anticipated changing from teaching amalgam placement before composite in five years. The mean proportions of posterior restorations placed clinically in permanent teeth using amalgam and composites were 52\% and 46\% respectively (range: amalgam $=20-95 \%$; composites $=5-70 \%)$. In five years' time, it is anticipated that the percentage of composite restorations placed clinically will increase from $46 \%$ to $50 \%$, while the percentage of amalgam restorations placed clinically will decrease from 52\% to approximately 40\% (anticipated ranges: composites $=15-80 \%$; amalgam 10-85\%).

\section{Teaching - deciduous teeth}

All ten centres taught the placement of preventive resin restorations in deciduous 


\begin{tabular}{|c|c|c|c|c|c|c|}
\hline \multirow{3}{*}{ Contraindications } & \multicolumn{4}{|l|}{ Permanent teeth } & \multicolumn{2}{|l|}{ Deciduous teeth } \\
\hline & $\begin{array}{l}\text { Occlusal cavities } \\
\text { premolars }\end{array}$ & $\begin{array}{l}\text { Occlusal cavities } \\
\text { molars }\end{array}$ & $\begin{array}{l}\text { Occl-prox cavi- } \\
\text { ties premolars }\end{array}$ & $\begin{array}{l}\text { Occl-prox } \\
\text { cavities molars }\end{array}$ & $\begin{array}{l}\text { Occlusal cavities } \\
\text { molars }\end{array}$ & $\begin{array}{l}\text { Occl-prox cavi- } \\
\text { ties molars }\end{array}$ \\
\hline & \multicolumn{6}{|c|}{ Number of training centres } \\
\hline Inability to place rubber dam & 2 & 2 & 5 & 5 & 2 & 2 \\
\hline Parafunctional activity & 1 & 1 & 2 & 2 & 1 & 1 \\
\hline Pathological wear & 0 & 1 & 0 & 1 & 1 & 1 \\
\hline Poor oral hygiene & 5 & 5 & 10 & 10 & 3 & 5 \\
\hline $\begin{array}{l}\text { Replacement of a large } \\
\text { amalgam restoration }\end{array}$ & 2 & 3 & 3 & 4 & 1 & 1 \\
\hline $\begin{array}{l}\text { History of allergy to } \\
\text { composite materials }\end{array}$ & 10 & 10 & 10 & 10 & 9 & 9 \\
\hline Atypical diet & 1 & 1 & 1 & 1 & 1 & 1 \\
\hline Large pulp & 0 & 0 & 0 & 0 & 0 & 0 \\
\hline Proximity to the pulp & 1 & 1 & 1 & 1 & 1 & 1 \\
\hline Denture abutment & 0 & 0 & 1 & 1 & 0 & 0 \\
\hline Subgingival margins & & & 9 & 9 & & 5 \\
\hline Temporomandibular dysfunction & 0 & 0 & 0 & 0 & 0 & 0 \\
\hline No valid aesthetic requirement & 0 & 0 & 0 & 0 & 1 & 1 \\
\hline Endodontically treated tooth & 2 & 2 & 3 & 4 & 2 & 2 \\
\hline Opposing composite restoration & 0 & 0 & 0 & 0 & 0 & 0 \\
\hline Susceptibility to caries & 6 & 6 & 6 & 6 & 6 & 6 \\
\hline Poor patient cooperation & 8 & 9 & 9 & 10 & 8 & 9 \\
\hline $\begin{array}{l}\text { History of postoperative pain with } \\
\text { posterior composite restorations }\end{array}$ & 4 & 4 & 4 & 4 & 2 & 2 \\
\hline Poor enamel quality & 3 & 3 & 4 & 4 & 3 & 3 \\
\hline $\begin{array}{l}\text { Buccolingual width of occlusal portion } \\
\text { is }<1 / 3 \text { of the intercuspal width }\end{array}$ & 0 & 0 & 0 & 0 & 0 & 0 \\
\hline $\begin{array}{l}\text { Buccolingual width of occlusal portion } \\
\text { is } 1 / 2 \text { of the intercuspal width }\end{array}$ & 0 & 0 & 0 & 0 & 0 & 0 \\
\hline $\begin{array}{l}\text { Buccolingual width of occlusal portion } \\
\text { is }>2 / 3 \text { of the intercuspal width }\end{array}$ & 2 & 2 & 3 & 3 & 0 & 0 \\
\hline $\begin{array}{l}\text { Buccolingual width of proximal box } \\
>1 / 2 \text { intercuspal width }\end{array}$ & 1 & 1 & 2 & 2 & 1 & 1 \\
\hline
\end{tabular}

molar teeth. Nine of the ten centres taught the placement of composite restorations in occlusal cavities in deciduous teeth, four schools taught composite placement in two surface occlusoproximal cavities, and two schools taught resin composite placement in three surface occlusoproximal cavities in deciduous molars. Many schools commented that they rely heavily on the use of a range of materials and procedures for the restoration of deciduous molar teeth, in particular in multisurface scenarios. The materials taught included amalgam, glass-ionomer cements and resin modified glass-ionomer cements, together with stainless steel crown techniques.

In five years' time, it was anticipated by nine centres that their teaching will include the placement of composites in occlusal cavities in deciduous teeth, and six centres anticipated teaching the placement of composites in two and three surface occlusoproximal cavities in deciduous molars. One school which did not teach the placement of composites in occlusal cavities in deciduous teeth, and four schools which did not teach the placement of composites in two and three surface occlusoproximal cavities in deciduous molar teeth, did not anticipate introducing such teaching over the next five years.

The mean proportions of posterior restorations placed clinically in deciduous molar teeth using amalgam and composites were found to be $26 \%$ and $22 \%$, respectively (range: amalgam = 0-75\%; composites = 0-50\%). In five years' time it is anticipated that the percentage of composite restorations placed clinically in deciduous molar teeth will increase from $22 \%$ to $33 \%$, while the percentage of amalgam restorations placed clinically in deciduous molar teeth will decrease from 26\% to 12\% (anticipated ranges: resin composite $=10-70 \%$; amalgam 0-50\%). 


\section{Cavity preparation}

In contrast to cavity preparations for posterior amalgam restorations, the design features taught for posterior composite restoration cavities included:

- Minimal cavity preparations, with no 'extension for prevention' - eight centres (80\%)

- 'Slot type' cavities (ie no occlusal component) - seven centres (70\%)

- Rounded internal line angles - six centres (60\%)

- Bevelled occlusal margins - four centres (40\%)

- Bevelled proximal box margins - three centres (30\%).

\section{Contraindications}

The contraindications taught to the placement of posterior composites in permanent and deciduous teeth are summarised in Table 1. The most common contraindications to the placement of posterior composites were a history of allergy to resin-based composite materials (ten centres), poor oral hygiene (ten centres when placing occlusoproximal restorations) and poor patient cooperation (ten centres when placing occlusoproximal restorations).

\section{Moisture control}

All ten schools reported that they taught the placement of a rubber dam when placing posterior composites. However, other forms of moisture control were taught also, including cotton wool rolls (ten centres), the use of a dry guard (ten centres) and the use of gauze (two centres).

\section{Bases and liners}

Techniques taught for the protection of operatively exposed dentine, including the use of liners and bases under posterior composites, are reported in Table 2. 'Totaletch' techniques were favoured for cavities involving the outer one third of dentine only (nine centres). Such techniques were not included in any of the programmes for deeper cavities involving the middle or inner-third of dentine. In such situations the placement of glass-ionomer cement with or without a calcium hydroxide lining was preferred.

\section{Matrices and wedges}

Five centres taught the use of transparent

Table 2 Teaching in respect of the management of operatively exposed dentine before the placement of posterior composites

\begin{tabular}{|l|l|l|l|} 
& $\begin{array}{l}\text { None } \\
\text { ('total-etch') }\end{array}$ & $\begin{array}{l}\text { Calcium hydroxide }+ \\
\text { glass ionomer cement }\end{array}$ & $\begin{array}{l}\text { Glass-ionomer } \\
\text { cement only }\end{array}$ \\
\hline & \multicolumn{2}{|l|}{ Number of training centres } \\
\hline $\begin{array}{l}\text { Shallow cavities } \\
\text { (outer third of dentine) }\end{array}$ & 9 & 0 & 1 \\
\hline $\begin{array}{l}\text { Moderate cavities } \\
\text { (middle third of dentine) }\end{array}$ & 1 & 3 & 7 \\
\hline $\begin{array}{l}\text { Deep cavities } \\
\text { (inner third of dentine) }\end{array}$ & 0 & 10 & 4 \\
\hline
\end{tabular}

Table 3 Who directs the teaching of operative dentistry teaching courses to dental therapy students?

\begin{tabular}{l|l|l|l|l} 
& Dental therapist & Visiting GDP & $\begin{array}{l}\text { Clinical Lecturer/ } \\
\text { Senior Lecturer }\end{array}$ & $\begin{array}{l}\text { Hospital specialist/ } \\
\text { Consultant }\end{array}$ \\
\hline & Number of training centres \\
\hline Preclinical course & 4 & & 7 & 2 \\
\hline Clinical course & 4 & 1 & 5 & 3
\end{tabular}

Table 4 What is the percentage contribution of the following groups of staff to the clinical supervision of dental therapy students?

\begin{tabular}{l|l}
\hline Staff member & $\%$ mean contribution \\
\hline Dental therapist & mean: $40 \%($ range $=0-85 \%)$ \\
\hline Visiting GDP & mean: $22 \%($ range $=0-100 \%)$ \\
\hline Clinical Lecturer/Senior Lecturer & mean: $28 \%($ range $=10-50 \%)$ \\
\hline Hospital specialist/Consultant & mean: $11 \%($ range $=5-50 \%)$ \\
\hline
\end{tabular}

(cellulose-acetate) matrix bands and light-transmitting plastic wedges when placing occlusoproximal restorations. The other five schools taught the use of circumferential and sectional metal matrices with either wooden or flexible plastic wedges.

\section{Composites and bonding systems}

Nine centres taught the use of hybrid composites for posterior composites. In addition the teaching at two centres included the use of macrofilled and microfilled composites. The teaching at one centre included the use of a nanohybrid composite. The brands of composites most commonly taught were 'Spectrum TPH' (Dentsply DeTrey GmbH, Konstanz, Germany - six centres), 'Filtek Supreme' (3M ESPE, St Paul , MN, USA - four centres), and 'Z100' (3M ESPE, St Paul, MN, USA - two centres). The brands of bonding system most commonly taught were 'Prime \&t Bond NT' (Dentsply DeTrey $\mathrm{GmbH}$, Konstanz, Germany) - six centres and 'Scotchbond' (3M ESPE, St Paul, MN, USA) - three centres.

\section{Light curing}

Five centres taught the use of quartz-tungsten halogen light curing units (QTH) for the photoactivation of composites. Three centres taught the use of light emitting diode (LED) light curing units. Two centres taught both QTH and LED light curing technologies. No centres taught the use of plasma arc based light curing units.

\section{Finishing techniques}

All ten centres taught 'immediate' finishing of posterior composites. Popular finishing instruments include finishing diamonds (ten centres), finishing discs (nine centres) and finishing strips (nine centres). Six centres taught water-cooling when contouring with finishing diamonds.

\section{Fees}

Nine centres reported that no fees were charged for treatment provided by student dental therapists. One centre at which the student dental therapists provide treatment within general dental practices as part of their outreach teaching reported that 
standard NHS fees are charged to patients for their treatment.

\section{Teachers}

Details of the staff involved in delivering the teaching programmes in operative dentistry to student dental therapists are reported in Tables 3 and 4.

\section{DISCUSSION}

The second (Interim/2009) edition of Developing the dental team, ${ }^{15}$ the General Dental Council's guidance document on educational programmes for dental care professionals (DCPs), states that dental therapists should 'be competent at completing a range of simple procedures in restorative dentistry, including amalgam and tooth-coloured restorations in both permanent and primary dentitions'. From the findings of this study it may be concluded that most of the dental therapy training programmes included in the present study meet this requirement in relation to at least the permanent dentition, and that student therapists may be gaining increasing experience in the placement of posterior composite restorations in permanent teeth, with this experience being at the expense of experience in placing restorations of dental amalgam. At the time of this present study, $42 \%$ of posterior restorations placed clinically by dental therapy students were composite. This contrasts with the situation in 2004 in dental schools in UK and Ireland when $30 \%$ of posterior restorations placed by student dentists were reported to be composite. ${ }^{16}$ The corresponding figures for dental schools in the USA and Canada in 2004 were $30 \% 0^{17}$ and $37 \%{ }^{18}$ respectively. Recent (2008) surveys conducted in other countries - Iran ${ }^{19}$ and Japan ${ }^{20}$ - have reported that $42 \%$ to $45 \%$ of direct posterior restorations placed by dental students are composite. The dental schools in the UK, Ireland and North America are currently being re-surveyed in respect of teaching of posterior composites. The results, five years on from the 2004 findings, are awaited with interest in light of the findings of the present study.

Given that dental therapists in the UK may provide an increasing number of simple restorations in the provision of routine dental care, ${ }^{2,3}$ it is considered important that these members of the dental team receive instruction in state of the art operative dentistry. Modern approaches to the use of composites in preference to dental amalgam underpin the muchneeded adoption of minimally invasive dentistry. ${ }^{8,21,22}$ This in turn is anticipated in the medium to long term to reduce the economic burden on patients and healthcare providers, notably the NHS, as the need for more complex and expensive treatments, such as repeated total replacement of restorations of increasing size and complexity, root canal treatments and crowns will be reduced over the lifetime of the patient. Indeed, to help give momentum to the drive in the NHS for enhanced quality, innovation, prevent and productivity, it is suggested that the rate of change to minimally interventive dentistry and, as a consequence, increased use of composites in the restoration of posterior teeth, should be accelerated, thereby limiting the further growth of the so-called 'heavy metal generation' of patients highlighted in the recent review of the dental services provided by the NHS. ${ }^{23}$

Teaching of posterior composite techniques for the restoration of deciduous teeth is not as well established as the teaching of posterior composites in the restoration of permanent teeth. For the restoration of deciduous teeth most centres teach the use of alternative, more traditional techniques, including the placement of amalgam, together with the use of glass-ionomer cements and stainless steel crowns in preference to the use of composites. It is acknowledged that the evidence base for the use of resin composites in the restoration of deciduous molar teeth is less robust than the one for posterior composites in permanent teeth, and glass-ionomer cements and stainless steel crowns have well-established indications for use in restoring deciduous molars; however, the use of composites in such situations, in particular, when used with minimally interventive techniques, has a number of important advantages. Given these advantages, let alone the extent to which posterior composites are taught for the restoration of permanent teeth, it is possibly surprising that the teaching of posterior composites in the restoration of deciduous molars is not more extensive than found to be the case in the present study.

\section{Competence}

While the mean proportion of posterior restorations placed by trainee therapists in permanent teeth using composites was $46 \%$, the range was $5-70 \%$. To meet the requirement set by the GDC that dental therapists should be competent at completing a range of simple procedures in restorative dentistry, including amalgam and tooth coloured restorations in both permanent and primary dentition, ${ }^{15}$ it is suggested that the percentage of posterior teeth restored with composite would need to be higher than reported in certain centres. Furthermore, given the importance of the educational and clinical experience gained while in training, ${ }^{24}$ and trends toward the increasing use of tooth coloured and, in particular composites in state of the art operative dentistry, it is suggested that, subject to the needs and wishes of patients, the range of posterior restorations placed using composite should be increased.

\section{Techniques}

Despite the extent and well established nature of the teaching of the placement of posterior composites to student therapists, it is of note that there were important differences in the techniques taught in different centres and some of these techniques are not supported by available evidence. This, however, is not unlike the situation observed in related surveys in respect of the teaching of posterior composites to undergraduate dental students. ${ }^{14}$ These techniques include:

\section{Bevelling}

Four centres indicated that their student therapists were taught bevelling of occlusal cavosurface margins and three centres were found to teach bevelling of the proximal box margins. Both these techniques are widely recognised to be contraindicated in techniques for the placement of posterior composites. ${ }^{21}$ Bevelling of the occlusal cavosurface margin results in the incorporation of thin extensions of composite in the completed restoration which extends over the occlusal surfaces. These extensions of composite are at risk of fracture under occlusal loading. Furthermore when occlusal bevels have been included, it is typically difficult to identify the extent of the restoration, which may, in time, 
lead to unwarranted removal of healthy tooth tissue during subsequent operative procedures. Bevelling of the proximal box margins results in the unnecessary loss of enamel that contributes to the bonding and, in particular, the marginal seal of occlusoproximal composite restorations. This is especially problematical along the gingival margin, where the loss of enamel caused by bevelling can result in the exposure of dentine and cementum, neither of which create reliable bonding and marginal seal. Furthermore, when bevelling of box margins is extended apical to the maximum convexity of the tooth, difficult to remove, flash excess may be created during restoration placement, depending on the nature and sufficiency of the matrix.

\section{Total etch}

As in the teaching of dental students, ${ }^{14}$ the present study revealed limited teaching of 'total etch' techniques, with all centres teaching the placement of a glassionomer cement base, either with or without a liner under restorations involving either the middle or inner third of dentine. Avoiding the use of a base offers several attractions when placing posterior resin composites, including an increased surface area for bonding and an increased thickness of composite which limits the subsequent risk of bulk fracture. ${ }^{8}$ The use of bases under deep amalgam restorations is indicated given the risk of thermal conduction through amalgam resulting in pulpal pain. ${ }^{8}$ Composites do not conduct heat in a manner similar to amalgam and hence the need for a base is greatly reduced..$^{25}$ Many dental practitioners still place a base under posterior resin composites; ${ }^{9}$ however, the evidence for this legacy of amalgam techniques is limited, with the possible exception of situations in very deep cavities in which it may be necessary to place a base to protect an indirect or direct pulp cap.

\section{Matrices and wedges}

Regarding the placement of occlusoproximal restorations, five centres indicated teaching the use of transparent matrix bands and rigid light transmitting wedges. The use of these devices has been discredited due to the bands being stiffer and thicker than their metal counterparts, and thereby increasing the risks of open and unfavourably proximal contours and contacts. ${ }^{26}$ Rigid light transmitting wedges do not adapt to the curved gingival margin of the proximal box and as a consequence are associated with an increased risk of overhang production. ${ }^{8,26}$ Transparent matrix bands and light transmitting wedges were introduced at a time when it was considered that composites contracted in the direction of the polymerising light, but this has been disproven. ${ }^{27}$ Metal matrices, sectional or circumferential, used together with wooden wedges or elastic wedging systems, are the technique of choice when placing occlusoproximal composite restorations. ${ }^{28}$

It is evident from the findings of the present study that the teaching of posterior composites, in at least permanent teeth, is a well established feature of teaching programmes for dental therapy trainees in most of the training centres in the United Kingdom. This is to be welcomed as patients will benefit from this approach to, in particular, the management of diseased and damaged teeth amenable to minimally interventive techniques. Ongoing surveys of the teaching of posterior composites to undergraduate dental students will hopefully demonstrate all the positive features of the teaching reported in this paper. The variations found to exist between the training centres, both in respect of the extent and techniques taught could, however, be considered to be matters of concern. In addressing these concerns referral may be to consensus documents on the teaching of posterior composites, including the consensus document of the British Association of the Teachers of Conservative Dentistry. ${ }^{29}$ In addition, teachers of dental therapy trainees are to be encouraged to be increasingly engaged in research and related activities which will help to enhance standards in the expanding use of composites in the clinical practice of operative dentistry.

There are a number of limitations to our study such as certain schools not agreeing to participate and others failing to return a completed questionnaire. The data reported represent the teaching of posterior composites to $62 \%$ of the annual graduating dental therapist workforce in the UK, which of itself is a reasonable response rate for a questionnaire based study. However, the potential exists for a non-response bias, with schools who are less interested in this subject being less likely to return responses, and the results should be interpreted in light of this. Hopefully a greater response rate will be achieved when this group is re-surveyed in five years time.

\section{CONCLUSION}

Based on the results of this study, it is evident that the teaching of posterior composites, in at least permanent teeth, is a well-established part of most teaching programmes for student dental therapists in the UK. Some variation was noted between the various centres in respect to the amounts of clinical experience gained in the placement of posterior composites and in certain clinical techniques. In further developing the teaching of posterior composites to dental therapists, training centres should look to relevant consensus documents on this aspect of the teaching of operative dentistry.

1. Dyer T A, Robinson P G. Public awareness and socia acceptability of dental therapists. Int J Dent Hyg 2009; 7: 108-114.

2. Ward P. The changing skill mix - experiences on the introduction of the dental therapist into general dental practice. Br Dent J 2006; 200: 193-197.

3. Ross M K, lbbetson R J, Turner S. The acceptability of dually-qualified dental hygienist-therapists to general dental practitioners in South-East Scotland. Br Dent J 2007; 202: E8.

4. General Dental Council. Scope of practice. London: General Dental Council, 2009.

5. Rowbotham J S, Godson J H, Williams S A, Csikar J I, Bradley S. Dental therapy in the United Kingdom: part 1. Developments in therapists' training and role. Br Dent J 2009; 207: 355-359.

6. Personal communication. General Dental Council's Registration Team. 28 September 2009.

7. Wilson N H F, Dunne S M, Gainsford I D. Current materials and techniques for direct restorations in posterior teeth. Part 2: resin composite systems. Int Dent J 1997; 47: 185-193.

8. Lynch C D. Successful posterior composites. London: Quintessence Publishing Co, 2008.

9. Gilmour A S M, Latif M, Addy L D, Lynch C D. Placement of posterior composite restorations in United Kingdom dental practices: techniques, problems, and attitudes. Int Dent J 2009; 59: 148-154.

10. Gilmour A S M, Evans P, Addy L D. The use of composite materials in posterior teeth in general dental practice. Br Dent J 2007; 202: E32.

11. Burke F J T, McHugh S, Hall A C, Randall R C Widstrom E, Forss H. Amalgam and composite use in UK general dental practice in 2001. Br Dent J 2003; 194: 613-618.

12. Manhart J, Chen H, Hamm G, Hickel R. Review of the clinical survival of direct and indirect restorations in posterior teeth of the permanent dentition. Oper Dent 2004; 29: 481-508.

13. Opdam N J, Bronkhurst E M, Roeters J M, Loomans $B$ A. A retrospective study clinical study on longevity of posterior composite and amalgam restorations. Dent Mater 2007; 23: 2-8.

14. Lynch C D, McConnell R J, Wilson N H F. Trends in the placement of posterior composites in dental schools. J Dent Educ 2007: 71: 430-434.

15. General Dental Council. Developing the dental team - second edition (interim) 2009. London: General Dental Council, 2009.

16. Lynch C D, McConnell R J, Wilson N H F. The teaching of posterior composite resin restorations in undergraduate dental schools in Ireland and the United Kingdom. Eur J Dent Educ 2006; 10: 38-43. 
17. Lynch C D, McConnell R J, Wilson N H F. Teaching the placement of posterior resin-based composite restorations in US dental schools. J Am Dent Assoc 2006; 137: 619-625.

18. Lynch C D, McConnell R J, Wilson N H F. Teaching the use of posterior resin composites in Canadian dental schools: how do current educational practices compare with North American trends? J Can Dent Assoc 2006; 72: 321.

19. Sadeghi M, Lynch C D, Wilson N H F. Trends in dental education in the Persian Gulf - an example from Iran: contemporary placement of posterior composites. Eur J Prosthodont Restor Dent 2009; 17: 182-187.

20. Hiyashi M, Seow L L, Lynch C D, Wilson N H F. Teaching of posterior composite restorations in Japanese dental schools. J Oral Rehabil 2009; 36: 292-298.
21. Roeters J J M, Shortall A C C, Opdam N J M. Can a single composite resin serve all purposes? Br Dent J 2005; 199: 73-79.

22. Burke F J T, Shortall A C C. Successful restorations of load-bearing cavities in posterior teeth with direct replacement resin-based composite. Dent Update 2001; 28: 388-398.

23. Steele J S. An independent review of NHS dental services in England. 2009. Available from: http://www.dh.gov.uk/en/Healthcare/ Primarycare/Dental/DH_094048 [Accessed 27 September 2009.].

24. Mjör I, Wilson N H F. Teaching of Class I, Class II direct composite resin restorations: results of a survey of dental schools. J Am Dent Assoc 1998; 129: 1415-1419.

25. Van Noort R. Introduction to dental materials, 3rd ed. Mosby, 2007

26. Mullejans R, Badawi M O, Raab W H, Lang H. An in vitro comparison of metal and transparent matrices used for bonded Class II resin composite restorations. Oper Dent 2003; 28: 122-126.

27. Versluis A, Tantbirojn D, Douglas W H. Do dental composites always shrink toward the light? J Dent Res 1998; 77: 1435-1445.

28. Loomans B A, Opdam N J, Roeters F J, Bronkhorst E M, Burgersdijk R C. Comparison of proximal contacts of Class II resin composite restorations in vitro. Oper Dent 2006; 31: 688-693.

29. Lynch C D, Stewardson D A, Shortall A C C, Tomson $P$ L, Burke F J T. Teaching posterior composite resin restorations in the United Kingdom and Ireland: Consensus views of teachers. Br Dent J 2007; 25: 183-187. 